\title{
PRESENTACIÓN
}

La Revista InterSedes se complace en presentar un nuevo número de manuscritos, todos ofreciendo una muestra del trabajo investigativo y docente que en nuestra alma mater se lleva a cabo.

En esta ocasión, las contribuciones provienen de Guanacaste (Olivares, Bermúdez), Turrialba (Castillo), Heredia (Elizondo y Monge), San José (Díaz, Solano y Amador, Chang, Aragón) y Argentina (Sandí y Cruz). La mayoría de las contribuciones provienen de estudios de posgrado, proyectos de investigaciones y estudios interinstitucionales. Otros provienen de un análisis crítico del trabajo docente.

La temática representada en el presente número amplía los horizontes a la relación entre la fe religiosa y la ciencia (Aragón) un tema muy presente en nuestro campus universitario, al patrimonio cultural intangible costarricense (Chang). Los resultados de investigaciones en materia de educación (Olivares, Sandí y Cruz) no faltan con sus aportes para el mejoramiento de los procesos de aprendizaje y enseñanza. El estudio del clima del Caribe y su registro histórico (Díaz, Solano y Amador), una reflexión historiográfica de la composición musical (Castillo). Finalmente, la producción agrícola (Elizondo y Monge), así como los procesos para la toma de decisiones propias de las Pymes (Bermúdez).

Como es de todos y todos conocidos, una publicación periódica requiere de aportes colectivos como los pares evaluadores y los Consejos Editoriales y Científicos, pero también de los criterios e indicadores de evaluación. En nuestro caso, UCRIndex recientemente ha planteado nuevos retos con otros indicadores que garanticen la calidad científica de las publicaciones de la Universidad de Costa Rica. En consecuencia, el trabajo editorial de este año se intensifica, y se espera que los resultados finales sean los esperados por la comunidad universitaria.

Sin más que anotar, el aporte de la Revista InterSedes a la producción científica está en sus manos.

M. Ph. Jimmy Washburn

Director, Revista InterSedes 


\section{Observaciones meteorológicas en la Región Caribe de Costa Rica}

(1833-1949)

Meteorological Observations in the Caribbean Region of Costa Rica (1833-1949)

RONALD E. DÍAZ BOLAÑOS ${ }^{1}$

FLORA J. SOLANO CHAVES $(\dagger)$

JORGE A. AMADOR ASTÚA ${ }^{2}$

\section{Resumen}

El presente artículo sintetiza los principales procesos histórico-científicos que permitieron el desarrollo de las primeras observaciones meteorológicas elaboradas en la región caribeña de Costa Rica. Se parte de las descripciones y mediciones realizadas por el Bachiller Osejo (1833) hasta la clausura parcial del Servicio Meteorológico y Sismológico Nacional (1949). Durante más de un siglo, dichas observaciones fueron elaboradas, sistematizadas y analizadas por diversos actores. Entre ellos, destacan científicos y estudiosos nacionales y extranjeros, instituciones científicas como el Instituto Físico-Geográfico Nacional y empresas como la United Fruit Company. Los datos recopilados fueron reanalizados e interpretados con el propósito de caracterizar el clima de la región en el pasado. Los resultados de este estudio aportan una línea base de comparación histórica ante el problema actual del cambio climático regional.

Palabras claves: Historia, meteorología, clima, Costa Rica, Caribe

\footnotetext{
1 Investigador, Centro de Investigaciones Geofísicas, Universidad de Costa Rica, roeddibo@yahoo.com

${ }^{2}$ Profesor, Escuela de Física, Universidad de Costa Rica, jorge.amador@ucr.ac.cr
} 


\begin{abstract}
This article summarizes the main historical and scientific processes that allowed the development of the first meteorological observations made in the Caribbean region of Costa Rica. It is part of the descriptions and measurements made by Bachelor Osejo (1833) to the partial closure of the National Weather and Seismological Service (1949). For over a century, these observations were made, systematized and analyzed by various stakeholders. Among them are domestic and foreign scientists and scholars, scientific institutions such as the National Physical Geographic Institute and companies like United Fruit Company. The collected data were re-analyzed and interpreted in order to characterize the climate of the region in the past. The results of this study provide a baseline for historical comparison to the current problem of regional climate change.
\end{abstract}

Keywords: History, Meteorology, Climate, Costa Rica, Caribbean

\section{Introducción}

El presente trabajo constituye una síntesis referente a los procesos históricocientíficos relacionados con el desarrollo de la meteorología en la Región Caribe de Costa Rica, la cual comprende la actual provincia de Limón y los cantones cartagineses de Turrialba y Jiménez. Estas regiones están vinculadas a la dinámica económica, social y cultural de esta parte del país, además de los aspectos físicos que los caracterizan, entre ellos el clima.

Precisamente, esta región se diferencia de la mayor parte del país por la ausencia de una estación seca y desde un punto de vista histórico, fue integrada a la dinámica económica del Valle Central por medio de la construcción del Ferrocarril al Atlántico y a una red económica transnacional producto del desarrollo del cultivo del banano al finalizar el siglo XIX. Si bien es cierto que se han ubicado datos meteorológicos registrados por instrumentos en esta parte del país desde mediados del siglo XIX, la conformación del enclave bananero favoreció el surgimiento de una red pluviométrica que fue constituida inicialmente por el Instituto Meteorológico Nacional y fue continuada por el Instituto Físico-Geográfico Nacional.

Este trabajo de investigación se basa en una recopilación bibliográfica de fuentes primarias y secundarias procedentes de archivos y bibliotecas, especialmente del Archivo del Museo Nacional de Costa Rica, el Archivo Histórico Arquidiocesano Mons. Bernardo Augusto Thiel Hoffmann, la Biblioteca Nacional Miguel Obregón Lizano, el Sistema de Bibliotecas, Documentación e 
Información de la Universidad de Costa Rica y de los Archivos del Instituto Smithsoniano en Washington D.C. (Estados Unidos). Los textos investigados corresponden a fuentes documentales, libros y revistas de los que se extrajeron los datos meteorológicos, tanto cualitativos como cuantitativos, para la construcción de las tablas presentes en este artículo, así como datos relacionados con los procesos políticos, económicos, sociales y culturales que conformaron el desenvolvimiento histórico de la Región Caribe entre la década de 1830 y 1940.

El período de la investigación va de 1833, año en que se publicaron las Lecciones de Geografía del Bachiller Osejo (primer texto impreso sobre geografía y meteorología de Costa Rica) hasta 1949, año en que se clausura parcialmente el Servicio Meteorológico y Sismológico Nacional en el marco de los cambios experimentados en el país durante la posguerra civil.

El objetivo del trabajo es analizar los datos meteorológicos cualitativos y cuantitativos registrados en la Región Caribe entre 1833 y 1949 con el propósito de relacionarlos con el contexto histórico de la época. Para ello se empleó el enfoque de historia social de la ciencia que permite establecer relaciones entre la actividad científica y los factores políticos, sociales, económicos, culturales y ambientales que perfilan el desarrollo científico en un determinado contexto histórico. Los detalles del marco de investigación en el que se planteó este trabajo se encuentran en Amador et al. (2013).

Este estudio ha sido organizado como sigue: La primera sección trata de las primeras observaciones atmosféricas en el Caribe de Costa Rica a partir de la década de 1830, periodo en que se imprimen los primeros libros en el país. La siguiente sección rescata el impulso que dio la construcción del ferrocarril en esa región, a las observaciones meteorológicas y al mejoramiento de las nociones de clima en esa vertiente. La creación del Instituto Físico-Geográfico al finalizar la década de 1880 fue determinante para incrementar las observaciones en esta región, aspecto que se trata en el siguiente apartado. Se presentan luego, dos secciones con datos e información sobre el desarrollo de las primeras predicciones en el Caribe y la contribución de la compañía bananera a la consolidación de una red de observaciones meteorológicas, en especial de precipitación. La última sección contiene las conclusiones de este estudio.

\section{Los primeros registros meteorológicos en el Caribe costarricense (1833-1870)}

Los primeros datos meteorológicos referidos a la Región Caribe en Costa Rica fueron recopilados por el Bachiller Rafael Francisco Osejo (¿1790-1848?) en sus Lecciones de Geografía (1833) donde aparece 
una caracterización climatológica del territorio costarricense (Zelaya, 1971, 69-70):

podemos considerar a Costa-rica dividida en dos partes: á saber Oriental y Occidental; en la inteligencia de que el dicho punto, no solo es remarcable por esta repartición de aguas; sino también por que su temperatura anuncia al viagero atento que se halla, en aquella altura, en la raya divisoria entre las dos grandes secciones del territorio. En las que la naturaleza creadora ostenta su poder bajo distintos grados y decoraciones. En la segunda accesible y suave casi en toda su extensin deciende por grados desde el temperamento delicioso y benigno que faborece la vegetación y alivia al hombre en sus diarias tareas hasta el ardor insoportable y la aridez que anuncia la esterilidad y languides. (sic)

Osejo en la cita anterior divide a Costa Rica en dos zonas, resalta la importancia de los ríos y define las características de acuerdo con la temperatura en cada región y consigna las ventajas del clima costarricense en relación con las actividades económicas (Zelaya, 1971, 7778):

Cual es el clima de Costa Rica? Es variado, asi como su aspecto y por las mismas causas. Contrayendonos á los puntos habitados y principales se - pag. 87- puede asegurar que el clima es el mas bello del mundo conocido pues que ni es excesivamente frío ni caliente. El

\begin{abstract}
Termómetro centígrado designa su temperatura entre el $11^{\circ}$ y $24^{\circ}$; pero queriendo hablar detodos los demas puntos ó visitados por la mano agricultora ó pastoril ú ocupados por alguna población se puede asegurar sin temor que recorre el Termomentro todos los grados ó desde el de la congelación á arriba y en proporción á la latitud que ocupa. (sic)
\end{abstract}

Otra mención referente a la Región Caribe es el informe presentado por Osejo ante las autoridades gubernativas sobre el Valle de Matina en 1833 (Osejo, 1948, 191) en el que señala:

pondera las riquezas del Valle de Matina; propone la creación de un Pueblo Nuevo; alaba su situación geográfica: manifiesta su importancia, como uno de los mejores puntos como puerto, en las costas centroamericanas; aconseja la mejora del camino que allá conduce y el aprovechamiento del curso del río para la navegación fluvial.

Osejo compara las riquezas del limo o tierra vegetal de Matina con las propiedades y efectos provocados por la inundación del Nilo, él lo bautiza como el "Exipto costarricense". Además, las conclusiones de Osejo fueron ampliadas por parte del ingeniero inglés Enrique Cooper ( $i$ ?) en su reporte sobre el Valle de Matina (1838), reimpreso en 1896, en el que expresa los siguientes conceptos respecto a las condiciones hidrográficas del río 
homónimo (ANCR, José Fidel Tristán

Fernández, 149.10, 10-11):

El bando Occidental del rio de Matina con la fuerza de las corrientes de este i las inundaciones, sufre muchos perjuicios, por lo que desbarranca en las orillas; llevándose anualmente ocho ó diez varas de terreno ... En este paraje hai muchos palos trahidos por las crecientes i lluvias grandes; i como están pegados en el fondo del Rio son peligrosos en la noche para la navegación, por causa de una corriente rápida de cinco millas por hora. En ambos lados del Rio hai ricos pastos de gamalote bueno para engordar Ganado i Bestias. (sic)

La labor de Osejo y Cooper fue continuada por el diplomático y agrimensor Felipe Molina Bedoya (1812-1855), autor de la obra Bosquejo histórico de la República de Costa Rica, seguido de apuntamientos para su historia (1851) que incluye un capítulo referente al clima de la naciente República de Costa Rica y lo describe de la siguiente manera empleando la escala Fahrenheit $\left({ }^{\circ} \mathrm{F}\right)$ para medir la temperatura (Molina, 1851, 28):

Es generalmente muy lluvioso, durante siete meses del año: cálido y sano en la costa del Pacífico: cálido y malsano en la del Atlántico, fresco y muy saludable en las mesas del interior, donde el termómetro no fluctua, sino de $65^{\circ}$ á $75^{\circ}$. En todo el curso del año. Se debe advertir que la estación de lluvias tiene lugar de
Abril á Noviembre en el interior y el lado del Pacífico, pero guarda un orden inverso en el lado del Atlántico. Aquí los meses referidos son secos y llueve de Noviembre á Febrero. (sic)

Este párrafo constituye una excelente descripción de los más importantes rasgos climáticos del país y constata la diferencia climática existente entre la costa pacífica y la caribeña, la cual empieza a ser estudiada en esa época por el señor Johann Otto von Oppeln ( $₫$ ?), quien fungía como comandante en Moín (Scherzer y Wagner, 1944, 217). Oppeln contó con la ayuda del otro comandante de dicho puerto, Pedro Boza ( $i$ ?), en el registro de datos meteorológicos en Moín, como lo consigna una carta enviada el 14 de marzo de 1853 al Ministro de Guerra y Marina. Aunque no se han podido localizar dichas observaciones, la nota anterior tenía reportes de un viaje efectuado por Oppeln de San José a Moín en febrero de 1853, consigna la presencia de "Ocho días con temporales y el camino muy malo" que afectaron su traslado a la costa caribeña (ANCR, Gobernación, 8046, 24f26v).

Paralelamente, la Junta Itineraria del Norte proyectó la construcción de un camino que atravesaría las llanuras orientales selváticas para finalizar en la costa del Caribe, por lo que se conformó una comisión encabezada por el Ing. Francisco Kurtze (m. 1868). Esta se puso en ruta el 9 de julio de 1853 con treinta y dos hombres, expuestos a las selvas, las 
enfermedades y a posibles incursiones de los indígenas viceitas (bribris). Es de destacar los pormenores y la acuciosidad de los resúmenes e investigaciones que presenta el científico austriaco Karl von Scherzer (1821-1903) en la sección titulada "Un viaje de exploración a través de los bosques vírgenes de las Cordilleras" (Scherzer y Wagner, 1944, 223), que narra gran parte de la travesía hacia la costa caribeña. En el camino, se encuentran con peones que estaban al servicio de la Sociedad Berlinesa de Colonización, dedicados a entresacar madera de los bosques. Una lluvia repentina les había impedido seguir el viaje y era usual para los trabajadores, apenas caen las primeras gotas de lluvia, guarecerse bajo un techo de hojas (Scherzer y Wagner, 1944, 224).

A lo largo de la travesía el Dr. Scherzer llevó un diario donde anotaba sus observaciones y detalles del viaje. Por ser de interés científico se resumirá algunos acontecimientos relevantes y que tienen relación con la toma de datos de temperatura, el equipo y otras variables. El viaje se realizó durante la estación lluviosa, aunque esta zona se caracteriza por continuas precipitaciones, tempestades y ríos de fuertes corrientes. A partir del 10 de julio de 1853, el Dr. Karl von Scherzer anotó con la precisión del caso, el instrumental y las condiciones que las circunstancias le brindaban, las observaciones y detalles que le deparaba la exuberante naturaleza y el sistema climático que reinaba en las diferentes localidades visitadas. No obstante, debido al estado de salud del Ing. Kurtze, la expedición fracasa y emprende su retirada a partir del 24 de julio de 1853.

A modo de resumen desde el punto de vista climatológico, Scherzer $(1944,243)$ reitera la diferencia climática entre ambas costas del país y recaba algunos de los datos que Oppeln registró en Moín en 1853:

que la costa oriental comparte primero el camino de las estaciones con la zona moderada (*); en el Pacífico al revés, dura el invierno o la estación lluviosa, de marzo a diciembre, y el verano, la estación seca, de diciembre hasta fines de abril. Pero hay que establecer, con todo, el límite hasta donde afecta esta diversidad climática el lado del Atlántico y la costa del Pacífico; si por ejemplo, las selvas del Chirripó comparten el cambio de las estaciones con la costa atlántico, y la del Pacífico, etc.

Un ciudadano de Cartago que lleva muchos años en la costa atlántica y que, como comandante militar, tenía bastantes ratos de ocio para observa el tiempo, nos contaba que la estación seca duraba en la costa apenas tres meses al año, es decir agosto, septiembre y octubre; todo el resto del año, en cuanto al tiempo se refiere, es sumamente incierto e inconstante.

Según una información del comandante actual del puerto de Moín, señor von Oppeln, alemán por nacimiento, llovió en los primeros cinco meses del año 1853, de enero hasta marzo, durante setenta y siete 
días y setenta y cuatro noches. La temperatura media en esta época fué de $89^{\circ}$ de F. En el mes de mayo, cuando comúnmente empieza en la parte occidental la estación lluviosa con fuertes aguaceros, llovió en la costa oriental, durante 18 días y 15 noches. Predominaban los vientos del Norte y Noroeste. La temperatura media de este mismo mes fué de $80^{\circ}$ de F. Un cuadro meteorológico sinóptico del año 1845 que obtuvimos por casualidad, indica en la costa atlántica para este año 105 días lluviosos, 30 sin lluvia, 120 variables y 110 de estación seca.

Una década más tarde, Felipe Valentini (18241899), ingeniero italiano que participaría en el proyecto de construcción del Ferrocarril al Atlántico, realiza observaciones en la zona de Limón (1865-1866) y los datos recopilados aparecen en la siguiente tabla:

\section{Tabla 1}

Datos meteorológicos tomados por el Ing. Felipe Valentini en Limón (1865-1866)

\begin{tabular}{|c|c|c|c|c|c|}
\hline \multirow[t]{2}{*}{ 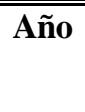 } & \multirow[t]{2}{*}{ "Mes } & \multicolumn{2}{|c|}{ Temperatura } & \multicolumn{2}{|c|}{ Precipitaciones } \\
\hline & & $\left({ }^{\circ} \mathrm{F}\right)$ & $\left({ }^{\circ} \mathrm{C}\right)$ & Pulgadas (") & Milímetros (mm) \\
\hline \multirow[t]{3}{*}{1865} & Octubre & 80.1 & 26.7 & 1.73 & 43.9 \\
\hline & Noviembre & 78.1 & 25.6 & 12.71 & 322.8 \\
\hline & Diciembre & 78.8 & 26.0 & 4.83 & 122.7 \\
\hline \multirow[t]{8}{*}{1866} & Enero & 77.4 & 25.2 & 23.33 & 592.6 \\
\hline & Febrero & 77.2 & 25.1 & 6.83 & 173.5 \\
\hline & Marzo & 76.5 & 24.7 & 3.67 & 93.2 \\
\hline & Abril & & & 3.33 & 84.6 \\
\hline & Mayo & 81.9 & 27.7 & 4.00 & 101.6 \\
\hline & Junio & 80.6 & 27.0 & 4.42 & 112.3 \\
\hline & Julio & 79.7 & 26.5 & 5.00 & 127.0 \\
\hline & Agosto & 79.8 & 26.6 & 9.38 & 238.3 \\
\hline
\end{tabular}

Fuente: Smithsonian Institution Archives. Meteorological Project, 1849-1865 + related records from 1820. Record 60. Boxes 13 \& 16.

La Figura 1 muestra la distribución mensual de los datos de la Tabla 1, en donde la temperatura y la precipitación están dados en ${ }^{\circ} \mathrm{C}$ y $\mathrm{mm}$, respectivamente. Aunque el periodo de observación es corto, se observa en esta figura algunas de las características del clima en esta región central del Caribe costarricense, entre ellas, una disminución importante de lluvia en marzo y posiblemente en el octubre observado. Además se presentaron precipitaciones más 
fuertes en el periodo invernal del Hemisferio Norte (ver enero y febrero de 1866) correspondientes al empuje frío de altas latitudes hacia regiones tropicales. Este efecto se aprecia en el descenso de la temperatura durante el mismo periodo invernal. Es notable como estas características del clima de la región habían sido documentadas y explicadas parcialmente por el Br. Osejo en su libro Lecciones de Geografía, alrededor de tres décadas antes.

Con estos datos, finaliza un período donde se empiezan a sistematizar las primeras caracterizaciones del clima de la costa caribeña y se reconoce su diferencia con el de la costa pacífica, además se hacen los primeros registros meteorológicos del Caribe costarricense.

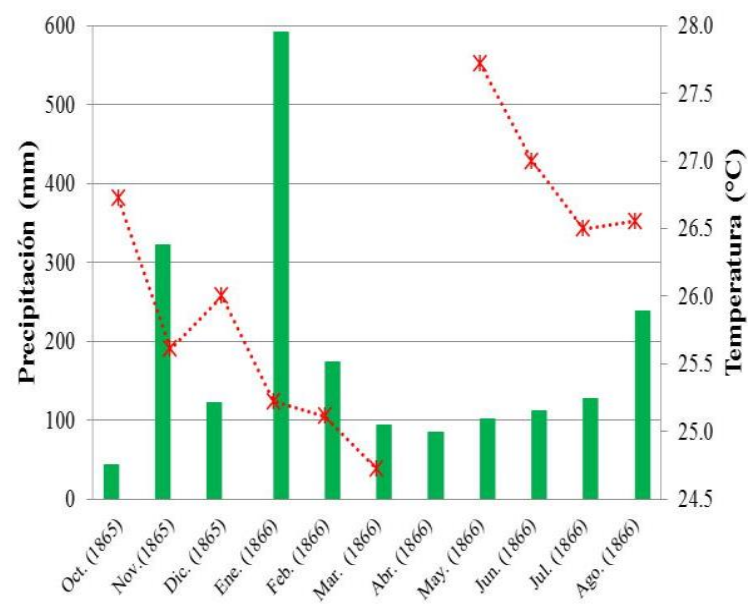

Figura 1. Observaciones realizadas por Felipe Valentini (1824-1899) de precipitación (mm, barras verdes) y temperatura $\left({ }^{\circ} \mathrm{C}\right.$, línea roja a trazos) en Limón durante el periodo Octubre 1865 - agosto 1866.
El proyecto de construcción del Ferrocarril al Atlántico y el clima en la región caribeña (1870-1890)

El proceso de construcción del Ferrocarril al Atlántico, implicó la realización de una fuerte inversión por parte de la compañía constructora y debido a las condiciones climáticas de la región caribeña, este proyecto se vio afectado por eventos hidrometeorológicos, principalmente por deslizamientos e inundaciones. Además, atrajo a miles de trabajadores, tanto del interior del país como más allá de sus fronteras, lo que favoreció la conformación de una población caracterizada por su diversidad étnica en la antigua comarca de Limón donde sobresalió la comunidad afrocaribeña, procedente principalmente de Jamaica (Stewart, 1976: 71-72 y 119-145; Murillo, 1995; Pérez, 1997: 61 y 67-68 y Molina, 2005: 50).

La obra fue iniciada por Henry Meiggs (1811-1877) y tras su muerte su sobrino Minor Cooper Keith (1848-1929) se hizo cargo de esta empresa (1879). Para su conclusión, Keith negoció el Contrato Soto-Keith (1884) con el Estado costarricense por medio del cual recibió unos 800000 acres de tierra, buena parte de los cuales fueron denunciados en la costa caribeña donde fueron sembrados de banano y el producto de las plantaciones sirvió para financiar los trabajos finales de la construcción del ferrocarril (Pérez, 1997, 63-64 y Molina, 2005, 49-50). Keith contrajo matrimonio con 
María Cristina Castro Fernández (1861-1944) en 1883, hija del expresidente y fundador de la República, Dr. José María Castro Madriz (1818-1892), aspecto que favoreció la asociación de la élite política y económica nacional con sus proyectos empresariales (Stewart, 1976; Gutiérrez, 1981, 89; Murchie, 1981, 340-347; García, 1992, 116-119 y 161164; Pérez Brignoli, 1997, 63 y Sáenz et. al, 2001, 285).

Durante las labores de construcción del ferrocarril, el eje conocido como Línea Vieja, que iba desde Carrillo (antiguo asentamiento donde finalizaba el antiguo camino que comunicaba San José con las llanuras caribeñas atravesando el Paso de la Palma) y Siquirres fue afectado severamente por los temporales de noviembre de 1886, que causaron "formidables avenidas" en el "correntoso" Toro Amarillo y en los ríos Madre de Dios, General, General Pequeño, Quebrada Gata, Caño Seco y Sucio, derribando sus puentes ferroviarios (La Gaceta, 12-XI-1887, 678). Estos puentes fueron sustituidos por otros provisionales, sin embargo, las grandes avenidas producidas por los temporales de inicios de 1888 provocaron la caída de los construidos en los ríos Sucio, Caño Seco, Quebrada Gata y General (La Gaceta, 9II-1888, 153).

El impacto conjunto de ambos eventos llevó al empresario Keith a solicitar al Congreso una prórroga del Contrato Soto-Keith para finalizar la vía y la importación de mano de obra extranjera. Por ello fueron contratados trabajadores italianos (tútiles), quienes al arribar al país protagonizaron el célebre movimiento huelguístico de 1888-1889, protestando contra las difíciles condiciones laborales en una zona de excesiva humedad y altas temperaturas (LG, 22-VIII-1889: 237; Stewart, 1976: 80-91; De La Cruz, 1984: $33-$ 35; Aguilar, 1989: 69-138; Murillo, 1995: 3940 y Pérez, 997: 63 y 67-68).

Casi al mismo tiempo, en diciembre de 1887, una tormenta tropical ingresa a territorio costarricense (Meléndez, 1996, 91 y Lizano y Fernández, 1996, 9), sin embargo, sus efectos fueron mínimos, de acuerdo con una investigación realizada por Díaz (2004-2005) en la que se estudió la documentación histórica y hemerográfica disponible tanto en el Archivo Nacional como en la Biblioteca Nacional. La Figura 2 muestra las trayectorias de tormentas y huracanes de 1887, entre ellas la de la tormenta tropical número 19 registrada entre el 7 y 12 de diciembre de ese año. 


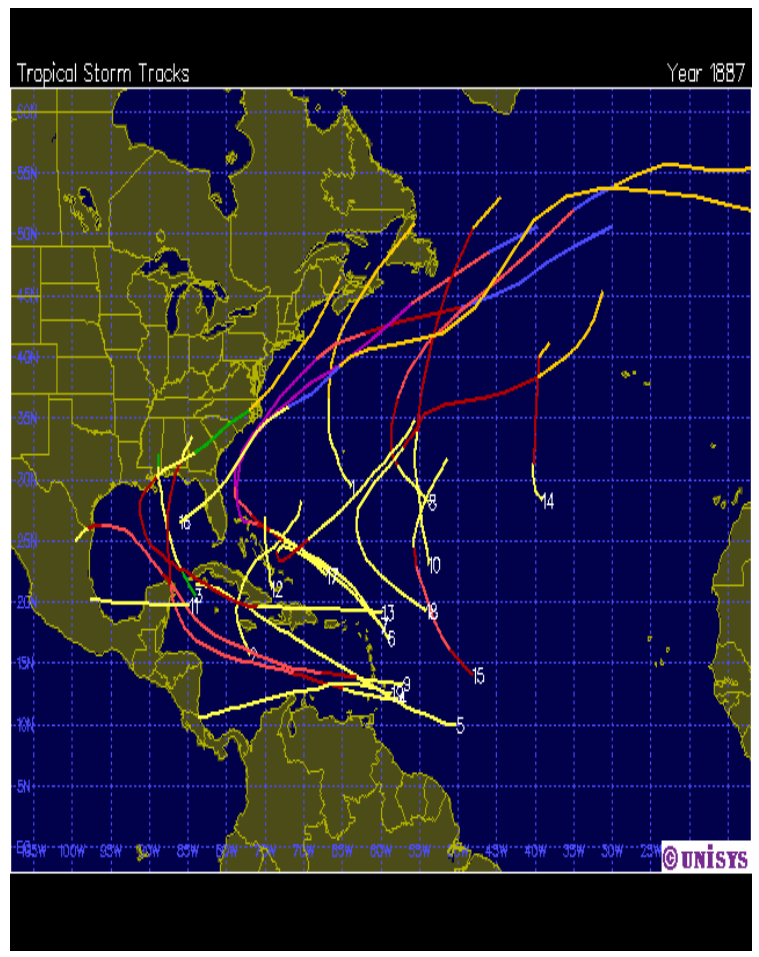

Figura 2. Trayectorias de las tormentas y ciclones tropicales de 1887. La tormenta tropical 19 (7-12 diciembre 1887) afectó la costa Caribe de Costa Rica causando daños menores.

Fuente

http://weather.unisys.com/hurricane/atlantic/18 87/index.php

Pese a las vicisitudes, la obra ferroviaria fue concluida en diciembre de 1890, después de finalizar el levantamiento de la Línea Nueva (eje ferroviario entre Cartago y Siquirres), donde los inconvenientes topográficos, geológicos, hidrográficos y climáticos se consideraron menores que los de Línea Vieja, más propenso a las inundaciones por la abundancia de ríos y deslizamientos (Conejo, 1972, 223-225; Murillo, 1995, 39; Pérez, 1997, 61-63 y Solano, 1999, 148-151).
Sin embargo, como lo han demostrado Peraldo y Rojas (1998) este ramal fue más afectado por deslizamientos y deslaves debido a la inestabilidad de los terrenos donde fue construido, especialmente en el sector comprendido entre Turrialba y Siquirres que corre paralelo al río Reventazón.

\section{El Instituto Físico-Geográfico y las} estaciones meteorológicas en el Caribe costarricense (1890-1930)

El Observatorio Meteorológico fue fundado en la ciudad de San José el 27 de diciembre de 1887 y fue la base del nuevo Instituto Meteorológico Nacional que surgió el 7 de abril de 1888 como resultado de la ampliación de los estudios meteorológicos en el país. A esta nueva entidad se le dotó de una serie de estaciones pluviométricas que conformaron la primera red meteorológica en Costa Rica, la cual incluyó una efímera estación en el puerto de Limón a cargo del Señor Charpentier, empleado aduanero que registró las precipitaciones del puerto y que por razones de salud tuvo que descontinuarlas (SIPRCR, 1889, VIII).

La apertura del Instituto FísicoGeográfico Nacional el 11 de junio de 1889 significó el inicio de una nueva etapa en el desarrollo de las observaciones meteorológicas en el Caribe con la fundación de las estaciones pluviométricas en Puerto Limón y en la Hacienda Aragón de Turrialba (1894), en cuyos 
predios se ubica actualmente el campus del Centro Agronómico Tropical de Investigación y Enseñanza (CATIE). A esa estación le siguieron las de Juan Viñas, Tuis, Boca del Río Banano, La Colombiana y Gute Hoffnung (IFGN, 1894, 65 y 68 y Díaz, 2003, 121).

Las estaciones que se establecieron en la Vertiente del Caribe fueron encargadas a empleados de las compañías vinculadas al empresario ferrocarrilero y bananero estadounidense Minor Cooper Keith, quien se convertiría en el vicepresidente de la United Fruit Company, compañía transnacional que surgió a raíz de la fusión de varias compañías fruteras que operaban en la cuenca del Caribe al finalizar el año 1899 (Pérez, 1997, 68-69 y Stewart, 1976).
Los datos obtenidos por algunas estaciones pluviométricas fueron publicados en el Boletín de Agricultura Tropical (1899) y corresponden a 1898, año considerado de "sequía extraordinaria" en la vertiente del Caribe y de excesiva humedad en el Pacífico. Lo de condición extrema no podría verificarse en este trabajo, sin embargo, es poco probable que estas anomalías estén relacionadas con alguna manifestación del fenómeno de El Niño - Oscilación del Sur (ENOS), esto de acuerdo al estudio de Amador y Muñoz (2014). De acuerdo con esta información, los datos correspondientes a las estaciones caribeñas aparecen en la tabla 2:

Tabla 2

Lluvia y días lluviosos en algunas estaciones de la red pluviométrica de Costa Rica (1898)

\begin{tabular}{|l|l|l|l|l|l|}
\hline Estación & $\mathbf{1 8 9 8}(\mathbf{m m})$ & $\begin{array}{l}\text { Días } \\
\text { observados }\end{array}$ & Término medio (mm) & $\begin{array}{l}\text { Días } \\
\text { Observados }\end{array}$ & Años \\
\hline Boca Banano & 2346 & 208 & 3092 & 219 & 3 \\
\hline Turrialba & 2246 & 134 & 2778 & 180 & 2 \\
\hline Juan Viñas & 2108 & 129 & 2137 & - & 2 \\
\hline
\end{tabular}

Fuente: Boletín de Agricultura Tropical, 15-I-1899: 16.

Resulta también de interés para la evolución de los conceptos meteorológicos, la descripción de un "huracán" en el Boletín de Agricultura Tropical que podría corresponder más a la de un vendaval (Boletín de Agricultura Tropical, 15-VI-1899, 95). La temporada de 1899 no muestra ningún sistema cercano a Costa Rica en la fecha indicada abajo (ver, http://www.nhc.noaa.gov/tracks/).

El día 18 de mayo de 1899, fue fecha nefasta para muchos de los cultivadores de nuestras fértiles llanuras del Norte. Un ciclón [sic], originado probablemente en 
alguna parte del Mar Caribe, alcanzó la costa cerca de la boca del río Matina y recorrió con rumbo de Este á Oeste, poco más ó menos, los bananales á lo largo del ferrocarril hasta Jiménez. Según parece resultar de los pocos informes fidedignos que hemos podido recoger, los daños mayores se encuentran al Este del río Reventazón, donde manzanas enteras de bananales han sido arrasadas y árboles gigantes atravesados en la vía férrea. Por alguna distancia al Oeste de la Junta, el eje de traslación del torbellino atmosférico siguió la especie de zanja que; en medio de la vegetación, forma el ferrocarril, y los bordes del mismo quedaron señalados entre los bananales por dos líneas gradualmente divergentes de cepas caídas, siendo más acentuados los daños del lado derecho. La traza del huracán [sic] se pierde allende el Toro Amarillo.

Fue precisamente en 1899 cuando la Oficina del Tiempo de los Estados Unidos adoptó el término "huracán", para designar a los vientos no frontales de escala sinóptica que circulan en torno a un sistema de baja presión, superando los 64 nudos o $120 \mathrm{~km} /$ hora y producidos en las aguas tropicales del Atlántico Norte y del Pacífico Oriental entre junio y noviembre, cuando la temperatura superficial de estos océanos se vuelve más cálida (NOAA, 1981, 2$4,11$ y $20-21)$.

El informe del año económico 18971898, elaborado por el Lic. Pedro Nolasco Gutiérrez (1855-1918), Jefe de la Sección
Meteorológica del Instituto Físico-Geográfico, comunicaba el desarrollo positivo de las labores de dicha entidad al manifestar la ampliación de la red pluviométrica a lo largo del Ferrocarril al Atlántico, gracias al apoyo brindado por la Costa Rica Railway Company para abrir estaciones en Río Hondo, Peralta, Siquirres y Swamp Mouth. La compañía autorizó a sus empleados la recolección de datos en forma gratuita, producto de la crisis económica que experimentaba el país al finalizar el siglo XIX, lo que impedía al gobierno contratar personal para dichas funciones (Conejo, 1972, 639 e IGN, 1989, 120).

La Sección Meteorológica del Instituto mantuvo a su cargo la coordinación de la red pluviométrica, integrada por más de treinta estaciones, distribuidas principalmente en el Valle Central y la Vertiente del Caribe, muchas de las cuales fueron manejadas e instaladas por el personal de la United Fruit Company (UFCO). Este hecho se relaciona con la activa colaboración brindada por el fundador de la compañía, Minor Cooper Keith y su sobrino John Meiggs Keith (m. 1927), al Instituto Físico-Geográfico, promoviendo el intercambio de publicaciones, la movilización del personal de la entidad y la llegada al país de científicos extranjeros, ligando las investigaciones científicas con el enclave bananero (Eakin, 1999, 138 у 143). 
El personal de la Sección Meteorológica veló siempre por la rigurosidad de las observaciones llamando la atención a los funcionarios que descuidaban sus obligaciones, por ejemplo, esta nota enviada por la Jefatura de esta sección al telegrafista de Limón, encargado de las observaciones en esta ciudad portuaria en 1903 (AMNCR, 8405, 38):

Desde algún tiempo se nota una gran irregularidad y poca exactitud en las observaciones practicadas por esa estación. Así es por ejemplo: que en várias ocasiones los datos referentes á la presión barométrica se han apuntado con un error evidentro [sic] de 5 milímetros. En las observaciones de la lluvia para el mes de Mayo [1903] encuentro que mientras en la estación vecina de Boca Banano hubieron 14 días de lluvia, Limón acusa solo 5 días y además las cantidades medidas, se hallan apuntadas con tan poca claridad que el total puede verse 16,6 como 166 milímetros. Usted comprenderá perfectamente que al hacerle esas indicaciones no quiero sino recordarle la absoluta necesidad de poner el mayor cuidado en la práctica del trabajo que le ha sido encomendado por este Servicio Meteorológico, no solamente en la manera de hacer las observaciones sino también en la de inscribirlas en los cuadros respectivos. Si se hubieran de repetir con frecuencia los defectos que dejo apuntados quitarían todo valor á sus observaciones. La lluvia debe medirse cada día á la hora de la primera observación de la mañana y no es preciso insistir en la necesidad de leer con cuidado la escala barométrica. (sic)

En la nota anterior se supone que debe de tener al menos igual número de días con lluvia, lo cual no parece ser fácil de obtener debido a la gran variabilidad espacial y temporal de la precipitación en esa zona (ver por ejemplo, Sáenz 2014). Otra nota, correspondiente también al año 1903 y enviada por la Sección Meteorológica del Instituto al Administrador del Ferrocarril al Atlántico señala las limitaciones que experimentaba el personal de las estaciones de la red pluviométrica para cumplir con su misión y mantener al día los registros meteorológicos elaborados en la Región Caribe (AMNCR, $8405,12)$ :

[Enmendado: Adjunto] remito á Usted cuadernos para las observaciones de la lluvia en las estaciones del ferro-carril, en donde se han establecido instrumentos para este objeto y además los duplicados que se han de remitir mensualmente á este centro con los datos correspondientes.

Siento tener que manifestar á Usted que el servicio de [enmendado: eses] estaciones ha dejado mucho que desear durante los últimos meses [1902]. La estación de Las Lomas [enmendado: envia] sus datos con la mayor irregularidad y las de Swamp Mouth, Guápiles, Peralta, Juan Viñas, 
Paraíso nos han faltado para los meses de Octubre y Noviembre. $\mathrm{Y}$ en general [enmendado: ninguno] [entrerrenglonado: de los cuadros] se recibe á tiempo para incluirse en el informe que se envía mensualmente á Washington. Conociendo el interés que Usted siempre ha manifestado para el buen manejo de esas estaciones, me [enmendado: atrevo] á creer que Usted tendrá á bien dar los pasos necesarios para conseguir en adelante más regularidad. De mi parte estaré siempre listo para cumplir con cualquier indicación que Usted me dé á [enmendado: este] respecto.

Suplico á Usted asimismo tenga la bondad de mandar á recoger los cuadernos del año próximo pasado y de remitirlos á este Instituto. Por su medio tal vez sea posible completar las lagunas que se notan en los cuadros del referido año. (sic)

En el anexo 1 aparecen registradas las estaciones meteorológicas presentes en la Región Caribe entre 1894 y 1930.

\section{Las primeras predicciones meteorológicas y el Caribe costarricense (1930-1949)}

La década de 1930 trae consigo los efectos de la crisis del sistema capitalista en Costa Rica, la cual se inició con la quiebra de la Bolsa de Valores de Nueva York (1929). La crítica situación socioeconómica se reflejó en el aumento del descontento social que motivó la realización de movimientos como la Huelga Bananera de 1934 (Botey, 2005, 57-63 y 7581).

Además, este decenio fue fundamental para el desarrollo de la meteorología en Costa Rica. Precisamente, uno de los más trágicos incidentes aéreos de la historia de la aviación costarricense estuvo directamente relacionado con el estado del tiempo: la muerte del aviador hispano-mexicano Pablo Sidar (1897-1930) que en 1929 hizo un viaje de $41842 \mathrm{~km}$ por América Latina - y de su asistente Carlos Rovirosa (1901-1930), durante un vuelo sin escalas entre Oaxaca (México) y Buenos Aires (Argentina) e interrumpido a la altura de Puerto Limón el 11 de mayo de 1930 (Salguero, 1981, 138; Román, 1987, 192 y Ortiz, 2002, 46): "Llovía torrencialmente, el cielo estaba totalmente encapotado, y muchos tuvieron la impresión de que el pequeño avión 'Morelos', fue alcanzado por un rayo que lo fulminó ocasionando la explosión” (Jiménez, 1962, 93).

Así que el pronóstico del estado del tiempo se volvió una necesidad. Por eso, el Dr. Charles Borel Lauterburg (1896-1992) inició las primeras experiencias en cuanto a la predicción científica del tiempo. Borel (1934, 234) fue autor del texto "Datos meteorológicos del país", resumen del estado de la meteorología costarricense a mediados de la década de 1930, en el que se notan algunas continuidades de los decenios anteriores como 
la centralización de los trabajos del observatorio de San José y el control de la red pluviométrica en el Caribe por parte de la UFCO:

Hay [en Costa Rica] un servicio meteorológico oficial (Torre al sur del Museo Nacional). Ahí se registran los elementos del tiempo para San José. Estos se publican en el "Diario de Costa Rica" y en el anuario estadístico.

Unos finqueros hacen medidas de la lluvia y de la temperatura. El servicio más completo de la república es el de la United Fruit Co. Registra la cantidad de lluvias, las temperaturas extremas y la humedad en un gran número de fincas de la zona atlántica y del valle del Reventazón. Unos de estos datos aparecen a intervalos irregulares en "Climatological Date, West Indies and Caribbean Service", publicado por el Departamento de Agricultura de los Estados Unidos.

Una novedad de esta publicación es la inclusión de promedios mensuales de precipitación para diecinueve estaciones, algunas de ellas pertenecientes a la región caribeña (Guápiles, Limón, Boca Banano, Peralta, Turrialba, Juan Viñas y Sipurio), mientras otros proceden de las antiguas revistas del Instituto Físico-Geográfico, del Boletín de Fomento y de documentos inéditos (Borel, 1934, 234).
El desarrollo de las radiocomunicaciones en Costa Rica permitió al joven José Merino y Coronado (1913-1987) interesarse por la meteorología y gracias a la formación brindada por su profesor Charles Borel, pudo estudiar el funcionamiento de los fenómenos físicos que determinaban el clima costarricense, entre ellos, el movimiento de convección de masas de aire y centró su análisis en el Valle Central (Borel y Merino, 1934, 238):

La baja presión en el Caribe provoca una aspiración del aire de la zona atlántica, hacia el este. El aire de la meseta Central será solicitado hacia el litoral; bajando hacia el mar se calentará y por lo tanto, podrá admitir más humedad. Como consecuencia habrá buen tiempo en la zona de Limón, caracterizado por un cielo despejado hacia la Cordillera y por vientos del Oeste que llegan relativamente secos a la costa. Estos se cargarán de humedad al avanzar sobre el mar y se observará desde el litoral, las nubes (generalmente cúmulos) que se alejan de la costa hacia el oriente. A su vez, el aire del Pacífico se dirige hacia la Cordillera, enfriándose. Los cerros del Norte y el alto de Ochomogo se cubren de nubes. Soplan los vientos del W. sobre la Meseta, llevando humedad y provocando unos días de temporal. Cuando el ciclón es grande, por fin la humedad logra pasar la Cordillera y habrá ligeras lluvias del lado del Atlántico. Después de poco tiempo y de unas horas de calma, se restablece el equilibrio. Los alisios del Nor Este soplan 
de nuevo y al encontrar el aire saturado de humedad y al enfriarse, provocan fuertes lluvias en la zona de Limón. En resumen, el paso de un ciclón produce un cielo claro en Limón, mientras el tiempo se altera en el resto del país; el mal tiempo se hace pronto general y termina el efecto arreciando los temporales en la zona atlántica, mientras despeja y mejora el tiempo en el resto del país.

El estudio sistemático de las ondas de radio y sus alteraciones asociadas al estado del tiempo, llevó al equipo formado por Borel y Merino (1934, 235-241) a interesarse en los métodos de pronóstico meteorológico y para ello pudieron relacionar la ocurrencia de fenómenos atmosféricos con la calidad en la recepción de ondas procedentes de emisoras extranjeras y el comportamiento del tiempo en el Valle Central como en la zona de Limón.

La investigación de Merino estaba relacionada con las transmisiones radiales asociadas con el descubrimiento de la ionosfera, estudiada por el científico inglés Oliver Heaviside (1850-1925) a partir de los primeros informes de radio-operadores $y$ aviadores referentes a perturbaciones en las comunicaciones originadas por iones, causantes de reflejos en ondas de radio y alterados por las tormentas solares que producían la estática. $\mathrm{La}$ difusión de estos trabajos por el uso de la radio era visto como una alternativa para evitar las pérdidas ocasionadas por los fenómenos atmosféricos, estableciéndose un sistema moderno de previsión meteorológica y advertencia sobre los riesgos de ciclones tropicales y anticiclones para Costa Rica (Borel y Merino, 1934, 235-239 y Holmes, 1966, 2627 y 190-192).

La continuidad de la investigación meteorológica permitió la apertura de una Sección de Meteorología en la Escuela de Agricultura (1934), formando una red de estaciones en distintos puntos del país para obtener datos de lluvias, paralela a la red pluviométrica nacional (gran parte de ella en manos de la UFCO) y para 1935 incluía 22 estaciones, una de ellas ubicada en Sixaola (Schaufelberger, 1935, 286).

La reapertura del Instituto FísicoGeográfico (1941) por parte del Dr. Merino y Coronado en el campus de la Universidad de Costa Rica en el capitalino Barrio González Lahmann, logró rehabilitar la red pluviométrica nacional manteniendo la fusión de las estaciones controladas por el Observatorio y la antigua Escuela Nacional de Agricultura, además de la fundación de otras nuevas y la cooperación de las estaciones administradas por la United Fruit Company en el Caribe y el Pacífico (Merino, 1943 y MIRENEM-IMN, 1988, 11-361). Las estaciones correspondientes al Caribe durante este período están incluidas en la tabla del anexo 1. 
Al finalizar la década de 1940, con el surgimiento del Servicio Meteorológico y Sismológico Nacional (1944) y los cambios políticos generados por la Guerra Civil de 1948, permitieron la llegada del ingeniero Elliot Coen París (1921-1997) a la dirección de esta entidad, en una época crítica para la misma por lo que debió de ejercer su cargo ad honorem y recibir financiamiento por parte de la UFCO. Esto permitió sostener la institución y realizar algunas investigaciones meteorológicas, debido al interés de la compañía que controlaba buena parte de las estaciones de la red pluviométrica, tanto en la costa pacífica como caribeña (Solano y Páez, 1991, 254; Fernández, 1997, 3 y Díaz, 2003, 279-280).

Los recursos de la UFCO y el dinero aportado por Coen permitió al Servicio Meteorológico publicar en los Anuarios estadísticos (1948-1949), emitidos por la Dirección General de Estadística, los datos del Observatorio de San José, aún instalado en la Universidad de Costa Rica y treinta y tres estaciones, muchas de ellas pertenecientes a la red pluviométrica o manejada por personas e instituciones que ofrecieron su colaboración a la entidad. La Dirección General de Estadística recuperó temporalmente su función de publicar información meteorológica, como lo había hecho en el siglo XIX, gracias al proceso de reestructuración que tuvo esta entidad al modernizar las investigaciones estadísticas hechas en ese momento (1948) (Dirección
General de Estadística, 1948, 9-18 y 1949, 1125; Hernández y Jiménez, 1951, 10-13 y Solano, 1999, 152-180).

Los datos de temperatura $y$ precipitación de San José correspondientes al mes de abril de 1948, quedaron incompletos por la Guerra Civil. Sin embargo, algunas estaciones como las de El Cairo de Siquirres lograron recabar datos de temperatura y precipitaciones, mientras que las de Bristol, Limón, Monteverde de Limón y Siquirres reportaron precipitaciones para el citado mes a pesar del conflicto militar. Es claro que la guerra civil interrumpió el funcionamiento del Observatorio capitalino por los vínculos políticos de sus responsables y no así los de las estaciones que operaron normalmente aunque se encontraban en zonas afectadas por las acciones bélicas cuyos encargados posiblemente no se involucraron directamente en el conflicto armado (Dirección General de Estadística, 1948, 10 у 17 у 1949, 12, 17, 19, 22 y 24 y Díaz, 2003, 280-281).

\section{Los datos meteorológicos de la United Fruit Company y la Northern Railway Company}

Al finalizar el siglo XIX, la Northern Railway Company fue establecida por la United Fruit Company (1900), como subsidiaria para administrar las vías férreas que controlaba en la vertiente del Caribe y obtuvo una concesión por parte del Estado costarricense de construir un muelle en Limón, el derecho de ampliar las vías 
a partir de las rutas explotadas por la Costa Rica Railway Company (1902) y su arrendamiento hasta la caducidad del Contrato Soto-Keith (prevista para 1983) (Carvajal y Botey, 1991, 139-140).

Según Carvajal y Botey (1991, 140) estas medidas consolidaron "el monopolio sobre los ferrocarriles y la explotación bananera con su extensión al muelle que ya estaba bajo el control de Keith y la United". Este oligopolio incursionó en la meteorología, porque necesitaba informes sobre las condiciones pluviométricas a lo largo de la línea férrea, las fincas bananeras y el puerto que operaba $y$ garantizar con ello el sostenimiento de sus actividades económicas en la provincia de Limón (Cf. Viales, 1998).

La Compañía Bananera de Costa Rica, subsidiaria de la transnacional United Fruit Company, tuvo a su cargo la recolección de datos de precipitación y temperatura de las estaciones pluviométricas entre 1905 y 1948. En el fondo del Instituto Costarricense de Ferrocarriles (INCOFER), conservado en el Archivo Nacional de Costa Rica, hay registros de las estaciones que tuvieron una existencia más estable: Navarro, Pejivalle, Turrialba, Salvador, Iroquois, Colombiana, Indiana, Carmen, La Lola, Good Hope North, Bristol, Zent, Búfalo, Limón, Barmouth East, Bananito North, Supt's Hill Estrella y Siquirres (ANCR, Planos, 35873-1 y 35950; Schaufelberger,
1935, 286 y cf. Carvajal y Botey, 1991, 140141).

La primera serie de datos fueron trazados y corregidos por un funcionario de la Oficina del Ingeniero Jefe de la División Costa Rica de la United Fruit Company, identificado con las siglas E. S. R., autor del Atlantic Slope Rainfall Charts que registra las precipitaciones en la costa caribeña y empleó el sistema norteamericano de medidas de capacidad para la cantidad de lluvia (ANCR, INCOFER, 35873). A partir de 1948, la recolección de información meteorológica empezó a ser registrada por funcionarios de la Northern Railway Company hasta 1967, cuando dicha tarea la asumió el personal de la Finca Freeman hasta 1971 (en vísperas de la nacionalización de la Northern en 1972) (ANCR, Planos, 35950).

Los personeros de la compañía ferroviaria, a través del Roadmaster Office, efectuaron numerosos gráficos sobre los datos recolectados de los pluviómetros y aprobados por la Superintendencia (donde laboraba M. M. Marsh, uno de sus responsables). Estos pluviogramas se referían a los promedios de precipitaciones expresados en pulgadas para la estación de Limón correspondientes a diferentes períodos entre 1900 y 1944, acompañados por las isoyetas de Limón (19051924) y Las Lomas (1944); gráficos comparativos para Limón, Beverly, Zent, Siquirres, Las Lomas, Peralta, Turrialba, Juan 
Viñas, El Yas y San José y otro diagrama sobre las principales ciudades situadas en la línea férrea entre Alajuela y Limón (1923-1927 y 1928-1929) (ANCR, Planos, 35820-1. 35820-2, $35820-3,35873-2,35873-3,35874,35879$, $36006,36007-1$ y $36007-2$ ).

El fondo del INCOFER contiene registros pluviométricos más completos recopilados entre enero de 1940 y diciembre de 1949, con datos de temperatura y humedad relativa (1940-1941); elaborados y copiados por agentes de la East Coast Office de la Compañía Bananera de Costa Rica y por la Northern Railway Company en Limón para el período 1941-1948 (ANCR, INCOFER, 4747).

Las estaciones que enviaron datos para estos últimos registros fueron las de Limón, Zent, Siquirres, Turrialba, Juan Viñas, Guácimo, Las Lomas, Peralta y Pejibaye, además de Beverly, El Yas, Monteverde y Pandora (sustituida por Penshurt en 1941) y clasificadas en cuatro divisiones según su ubicación geográfica (Limón, Zent, Siquirres y Turrialba). Los datos recogidos eran promediados mensualmente y por cuatrienio (ANCR, INCOFER, 4747).

Algunos datos están incompletos, hecho atribuible a la escasez de personal preparado para la recolección de informes meteorológicos, al traslado de los funcionarios encargados de dicha tarea y al extravío de información. La Northern, al asumir dicha labor, se centró en la estación de Limón (1946), por ser el principal puerto de embarque de la Compañía Bananera y el destino final de la ruta ferroviaria y entre sus observadores se encontraban José Soto Z., Leopoldo Greenwood, C. W. Averre, C. O. Riggs y E. Aragón G. (ANCR, INCOFER, 4747).

Estos funcionarios hicieron sus propios análisis de los datos meteorológicos: Leopoldo Greenwood envió una carta al Ing. Enrique Góngora de la Oficina de Dibujo de San José, detectando un error en los datos de precipitaciones de Limón (julio de 1946) y F. M. Burns escribió una nota a C. W. Averre, el 1 de julio de ese año, comunicando el hallazgo de ciclos de siete y ocho años de extremos de sequedad y humedad, alternados en una secuencia de intervalos de 8-8-7-8-8-7 años en los registros pluviométricos de San José (18681946) (ANCR, INCOFER, 4747). Este estudio es importante, porque rescata los datos confeccionados por la Oficina de Estadística en el siglo anterior y preceden a los del Instituto Meteorológico Nacional (Solano, 1999, 152167), sin embargo, es necesario un estudio posterior para determinar su potencial relación con alguna señal interanual como por ejemplo la de El Niño - Oscilación del Sur (ENSO).

\section{CONCLUSIONES}

La Región Caribe debido a su posición geográfica con respecto a los principales centros económicos de América del Norte y de 
Europa Occidental, ha sido de gran importancia para el país, especialmente con la apertura del Ferrocarril al Atlántico que habilitó una ruta de comunicación entre el Valle Central y el Mar Caribe. Debido a sus condiciones climáticas características del trópico húmedo y a la ausencia de una estación seca bien definida, el conocimiento del estado del tiempo ha sido una constante para el desarrollo de las actividades económicas en esta zona del país, en particular el cultivo del banano, cuyos orígenes están íntimamente ligados con el proyecto ferrocarrilero desarrollado en el último tercio del siglo XIX, el cual a su vez atrajo una importante mano de obra extranjera que procedente de diversas partes del mundo y del interior del país, lo que hizo de la provincia de Limón un territorio de gran diversidad étnica y cultural.

Las condiciones climáticas la Región Caribe, caracterizada por la abundancia de precipitaciones y el consecuente desbordamiento de los ríos, explican porqué es una de las zonas del país donde históricamente ha habido una mayor presencia de estaciones meteorológicas, principalmente pluviométricas, que han venido recabando información por más de un siglo aunque muchas veces en forma discontinua. Los fenómenos hidrometeorológicos dificultaban el desarrollo de las comunicaciones entre este territorio, donde se encontraba el principal puerto de exportaciones hacia los mercados europeos y estadounidense, con el Valle Central, donde se desarrollaban las principales actividades económicas del país, en particular la producción cafetalera, que era enviada al extranjero especialmente a través de Puerto Limón, por donde también ingresaban a Costa Rica muchos de los productos manufacturados procedentes de las naciones industrializadas.

El interés de la empresa transnacional UFCO por tener un mayor conocimiento del comportamiento del clima de la zona donde se encontraban sus principales operaciones en Costa Rica, por lo menos hasta finales de la década de 1930 que empezó a trasladarlas al Pacífico Sur, hizo que se extendiera y mantuviera la red pluviométrica a lo largo de la primera mitad del siglo $\mathrm{XX}$, aspecto que se evidencia en la instalación de estaciones pluviométricas en fincas bananeras y estaciones ferroviarias y en el apoyo que se dio a las instituciones meteorológicas en tiempos de crisis. Se rescata de la documentación analizada la importancia que tuvo las primeras predicciones del tiempo para el manejo de las actividades de la región, en particular mediante la observación de la distorsión producida en las emisiones radiales por los ciclones en el Mar Caribe y el intento por recopilar y analizar los datos observados en las estaciones de la UFCO.

Es preciso indicar que la UFCO, brindó apoyo económico y logístico a la comunidad científica ligada a las instituciones meteorológicas, en particular con el sostenimiento de la red pluviométrica, como 
parte de lo que Viales y Clare (2009) denominan "régimen de cientificidad", un contexto en el que diversos actores gubernamentales, empresariales y científicos unen intereses para fomentar las actividades científicas, en particular aquellas ligadas a los procesos productivos, en este caso, el desarrollo de las comunicaciones ferroviarias y de la producción bananera en el Caribe costarricense.

Esta red de datos meteorológicos permitió la recopilación de información relacionada con el estado del tiempo y las condiciones climáticas del territorio del enclave de Limón, donde la UFCO controlaba además de las plantaciones bananeras y el proceso de producción de la fruta, las vías férreas, la actividad comercial y portuaria que tenían lugar en las tierras adquiridas por Keith a través del contrato firmado con el gobierno costarricense en 1884, por lo que se desarrolló un sistema de relaciones económicas y sociales basadas en el concepto de enclave, caracterizado por su dinamismo y complejidad, en el espacio ocupado por la compañía y en el que se definieron sus relaciones con el Estado costarricense, el poder local y los grupos subalternos vinculados con la actividad bananera (García, 1992 y Viales, 1993).

Es en este espacio donde el conocimiento meteorológico fue fundamental para orientar las actividades productivas, especialmente el desarrollo de plantaciones bananeras en un territorio húmedo y susceptible de inundaciones. No obstante, mucha de esta información que fue recopilada en las estaciones del Caribe costarricense, no se socializó con la población de la zona y se mantuvo en manos de la UFCO o del personal del Instituto Físico-Geográfico Nacional en sus diferentes etapas a través del siglo XX. Los registros meteorológicos generados por las estaciones de la UFCO pasaron a manos del Estado costarricense una vez que el Ferrocarril al Atlántico fue nacionalizado a inicios de la década de 1970, por lo que no estuvieron disponibles para su consulta y análisis hasta su posterior incorporación en el fondo documental del Instituto Costarricense de Ferrocarriles (INCOFER) del Archivo Nacional de Costa Rica.

Cabe señalar que ha sido hasta años recientes que la información meteorológica recopilada por estaciones situadas en la vertiente del Caribe se ha vuelto más accesible para los productores bananeros de esa región, gracias a la labor desarrollada por la Corporación Bananera Nacional (CORBANA) a través de su base de datos BANACLIMA. Esta entidad pública fue fundada con el nombre de Asociación Bananera Nacional (ASBANA) en 1971, precisamente cuando se gestaba el proceso de nacionalización del Ferrocarril al Atlántico y en el marco de las políticas desarrollistas impulsadas por el Estado costarricense. Dicha corporación cuenta también con una red de estaciones meteorológicas en la provincia de Limón y en 
el cantón herediano de Sarapiquí, cuyos datos han sido analizados por el personal científico del Centro de Investigaciones Geofísicas (CIGEFI) de la Universidad de Costa Rica, lo que ha permitido un mayor conocimiento del comportamiento de los fenómenos atmosféricos que tienen lugar en esta región del país y sus implicaciones en la producción bananera (Amador et al., 2013).

Finalmente, la recopilación de todos los datos meteorológicos recolectados en las estaciones de la provincia de Limón, tanto en el pasado como en el presente, así como su posterior análisis histórico-científico sería de gran utilidad pues permitiría tener un mayor conocimiento del clima y la variabilidad climática en la Región Caribe de Costa Rica y establecer comparaciones con otras regiones del Caribe centroamericano e insular que comparten similares condiciones climáticas y también han experimentado el desarrollo de la actividad bananera mediante la instalación de enclaves en sus territorios.

\section{Agradecimientos}

Este trabajo fue iniciado por la Lic. Flora Solano Ch. (†), investigadora de la historia de la meteorología regional. R.D. y J. A. reconocen su dedicación y entusiasmo por el tema y dedican este documento a su memoria. La presente investigación se realizó en el marco del Proyecto "El clima, la variabilidad climática y el cambio climático observados en la Vertiente Caribe de Costa Rica: Un estudio básico para la actividad bananera de CORBANA" (VI-805-B0402), adscrito al Centro de Investigaciones Geofísicas (CIGEFI) de la Universidad de Costa Rica, donde también contó con el apoyo del Programa de Estudios Sociales de la Ciencia, la Técnica y el Medio Ambiente (PESCTMA, VI-805-A4906). Se agradece también a Ingrid Rivera por su colaboración en la generación de las figuras incluidas en el presente artículo y a Carla Vega por su ayuda en la revisión del texto.

\section{Anexo 1}

\section{Estaciones meteorológicas de la Región Caribe de Costa Rica}

(1894-1949)

\begin{tabular}{|l||l|l|}
\hline \multicolumn{2}{|c|}{ Vertiente del Caribe } \\
\hline \hline 1894 & Hacienda Aragón de Turrialba & Fundada por el empresario Manuel \\
& & $\begin{array}{l}\text { Aragón Quesada } \\
(1844-1921) \text { y donde se instaló el } \\
\end{array}$ \\
& primer ingenio azucarero de Costa \\
& Rica. \\
\hline \hline
\end{tabular}




\begin{tabular}{|c|c|c|}
\hline & & 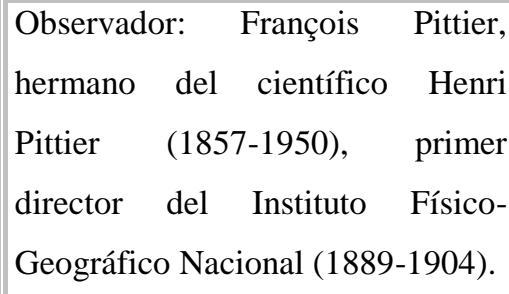 \\
\hline $1894,1898-1905$ у $1941-1949$ & Puerto Limón & $\begin{array}{l}\text { Uno de los puntos neurálgicos de } \\
\text { la red bananera controlada por la } \\
\text { UFCO, al ser el principal puerto de } \\
\text { embarque de la producción } \\
\text { costarricense enviada a Nueva } \\
\text { Orleáns, centro de acopio de las } \\
\text { frutas cultivadas en el Caribe. } \\
\text { Observadores: H. M. Feild, C. E. } \\
\text { (1894) y Zacarías Chévez (1903, } \\
\text { telegrafista). }\end{array}$ \\
\hline 1896 y 1906 & Tuis & $\begin{array}{l}\text { Datos de temperatura, estado de la } \\
\text { atmósfera, nebulosidad y presión } \\
\text { atmosférica. } \\
\text { Observadores: Frank P. Monroe } \\
\text { (1896) y Óscar Thiele (1906). }\end{array}$ \\
\hline $1896,1898-1901$ у $1944-1949$ & Gute Hoffnung / Good Hope & No hay datos disponibles. \\
\hline 1896 у $1898-1905$ & Boca del Río Banano & \\
\hline 1896 у $1898-1906$ & Juan Viñas & Observador: J. Brenes (1906). \\
\hline 1896 y $1904-1905$ & La Colombiana (Jiménez) & Estación ferroviaria. \\
\hline $\begin{array}{l}1897-1898, \quad 1900-1906, \quad 1923- \\
1928 \text { у } 1943\end{array}$ & Siquirres & $\begin{array}{l}\text { Observadores: S. S. Turey. (1897), } \\
\text { H. C. Smith y H. Brenes Díaz } \\
\text { (1906). }\end{array}$ \\
\hline 1898 & Río Hondo & No hay datos disponibles. \\
\hline \multirow[t]{2}{*}{$1898-1906$} & Swamp Mouth & $\begin{array}{l}\text { Observador: C. } \quad \text { Strasburguer } \\
\text { (1906). }\end{array}$ \\
\hline & Las Lomas & $\begin{array}{l}\text { Observadores: L. Coma y R. Casas } \\
\text { (1906). }\end{array}$ \\
\hline $1898-1906$ y 1943 & Peralta & $\begin{array}{l}\text { Observadores: B. M. Hess } \\
\text { y B. Moore (1906). }\end{array}$ \\
\hline 1900-1905 у 1943 & Guápiles & No hay datos disponibles \\
\hline
\end{tabular}




\begin{tabular}{|c|c|c|}
\hline $1900-1905$ & Sipurio de Talamanca & $\begin{array}{l}\text { Observador: Presbo. Agustín } \\
\text { Blessing Prinsinger (1868-1934), } \\
\text { miembro de la congregación } \\
\text { paulina, oriundo de Ravenstein } \\
\text { (Wurtemberg, Alemania), estudió } \\
\text { en el Gimnasio de Rottemburgo y } \\
\text { el Wilhelm-Stift de Tubinga } \\
\text { (Alemania), enviado a Costa Rica } \\
\text { para ejercer el profesorado en el } \\
\text { Seminario de San José (1893- } \\
\text { 1898), ordenado sacerdote por } \\
\text { Mons. Bernardo Augusto Thiel } \\
\text { (1894), encargado de la misión de } \\
\text { Talamanca (1899-1905), Rector } \\
\text { del Seminario (1905-1920) y } \\
\text { vicario apostólico de Limón (1921- } \\
\text { 1934). }\end{array}$ \\
\hline 1900-1906 у 1941-1949 & Zent & $\begin{array}{l}\text { Registró la temperatura a } \\
\text { distintos niveles del suelo, } \\
\text { como se hacía en San José y su } \\
\text { instalación fue obra del } \\
\text { botánico suizo Adolphe Tonduz } \\
\text { (1862-1921) y del empresario } \\
\text { John M. Keith. } \\
\text { Observador: Jacinto Xirinachs } \\
\text { Pérez (m. } \\
\text { Superintendente de la División } \\
\text { de Zent de la UFCO. }\end{array}$ \\
\hline 1901-1903 & Turrialba & No hay datos disponibles. \\
\hline 1901-1905 & Dos Novillos & \\
\hline
\end{tabular}




\begin{tabular}{|c|c|c|}
\hline & Bearesem Farm & \\
\hline $1902-1905$ & Chirripó Farm & \\
\hline \multirow[t]{7}{*}{ 1904-1905 } & Guácimo & \\
\hline & Iroquois & \\
\hline & La Argentina & \\
\hline & La Luisiana & \\
\hline & Madre de Dios & \\
\hline & Toro Farm & \\
\hline & Victoria Farm & \\
\hline 1904-1905 у 1949 & La Lola & \\
\hline $1905-1949$ & Freeman & \\
\hline 1923-1947 & Hacienda Dominica & \\
\hline 1926-1949 & Hacienda Rosemount de Juan Viñas & $\begin{array}{l}\text { Observador: Juan (John) Ernest } \\
\text { Monroe (1906-1992), autor de } \\
\text { los registros meteorológicos de } \\
\text { esta finca cafetalera } \\
\text { perteneciente a su familia. }\end{array}$ \\
\hline 1930-1942 & Río Jiménez & Información no disponible. \\
\hline $1938-1939$ у $1942-1949$ & El Cairo de Siquirres o Línea Vieja & \\
\hline
\end{tabular}




\begin{tabular}{|c|c|c|}
\hline 1942-1949 & IICA, Turrialba. & $\begin{array}{l}\text { El Instituto de Investigaciones } \\
\text { en Ciencias Agrícolas (IICA), } \\
\text { fundado en los predios de la } \\
\text { antigua Hacienda Aragón } \\
\text { (1942), bajo el patrocinio de la } \\
\text { Oficina de la Unión } \\
\text { Panamericana. } \\
\text { Hoy sus instalaciones son } \\
\text { ocupadas por el Centro } \\
\text { Agronómico Tropical de } \\
\text { Investigación y Enseñanza } \\
\text { (CATIE). } \\
\text { El IICA fue el centro de labores } \\
\text { del científico Leslie R. } \\
\text { Holdridge (1907-1999), autor } \\
\text { de una clasificación } \\
\text { bioclimática mundial } \\
\text { conformado por un sistema de } \\
\text { zonas de vida (1967). }\end{array}$ \\
\hline 1944-1948 & Bristol. & No hay datos disponibles \\
\hline 1944-1949 & San Clemente. & \\
\hline
\end{tabular}

Fuentes: AHAMBATH, 4, 254; AMNCR, 8405, 2, 11-13, 32, 38 у 70; 8515, 47; 2; 8530, 1-11 у Documento de Tuis, 1897, 1-7; Budowski y Schreuder, s.f., 1-16; Boletín del Instituto FísicoGeográfico Nacional, 1901-1903; Boletín de la Sociedad Nacional de Agricultura, I (3), 1906, 48; Gutiérrez, 1906a, 18 y b, 95; Kepner y Soothill, 1949; Conejo, 1972, 584 y 623-624; Murchie, 1981, 223-225 y 314-323; Blanco, 1984, 113-114; MIRENEM-IMN, 1988, 3-49, 65-121, 147-157, 197-205 y 271-274; Hartman, 1991, 43 y 69; Pérez, 1997, 68-69; Velásquez, 2000, 12-15 y 25 y 2002, 191-194. 


\section{FUENTES DOCUMENTALES}

Archivo del Museo Nacional de Costa Rica

(AMNCR)

Inventario General de Bienes (IGB), 8405,8530 y Documento, estado mensual de la atmósfra, ráfagas, tempestades, temblores, etc. en Tuis. Año 1897.

Archivo Histórico Arquidiocesano Monseñor Bernardo Augusto Thiel Hofmann (AHAMBATH).

Serie Gobierno Eclesiástico, Sección

Visitas Pastorales, Libro 4.

Archivo Nacional de Costa Rica (ANCR),

Fondo Instituto Costarricense de

Ferrocarriles (INCOFER), 35873, 4747.

Fondo José Fidel Tristán Fernández. Exp. 149.10 .

Fondo Planos, 35820-1. 35820-2, 35820-3, 35873-1, 35873-2, 35873-3, $35874,35879,35950,36006,36007-1$ y $36007-2$.

Serie Gobernación. Exp. 8046.
Smithsonian Institution Archives.

Meteorological Project, 1849-1865 + related records from 1820. Record 60. Boxes 13 \& 16.

\section{FUENTES HEMEROGRÁfICAS}

Boletín de Agricultura Tropical

15-I-1899, 16.

15-VI-1899, 95.

Boletín de la Sociedad Nacional de Agricultura I (3), 1906, 48.

Boletín del Instituto Físico-Geográfico Nacional

1901-1903

Dirección General de Estadística y Censos

Anuario Estadístico, 1948, 1949.

La Gaceta.

12-XI-1887, 678.

9-II-1888, 153.

22-VIII-1889, 237. 


\section{REFERENCIAS}

Aguilar, Ó. (1989). La huelga de los tútiles. 1887-1889. Un capítulo de nuestra historia social. San José, Costa Rica: EUNED.

Amador, J. A.; Alfaro, E. J.; Hidalgo, H. G.; Soley, F. J.; Solano, F.; Vargas, J. L.; Sáenz, F.; Calderón, B.; Pérez, P. M.; Vargas, J. J.; Díaz, R.; Goebel, A.; Montero, A.; Rodríguez, J. L.; Salazar, A.; Ureña, P.; Mora, N.; Rivera, I.; Vega, C. y Bojorge, C. (2013). Clima, variabilidad y cambio climático en la Vertiente Caribe de Costa Rica: Un estudio básico para la actividad bananera. Informe Final del Proyecto VI-805-B0-402. San José, Costa Rica: Centro de Investigaciones Geofísicas (CIGEFI), Vicerrectoría de Investigación y Escuela de Física, Universidad de Costa Rica y Corporación Bananera Nacional (CORBANA).

Amador, J. A. y Muñoz, G. (2014). Moduladores climáticos de baja frecuencia y las plagas de langostas en Mesoamérica. En G. Peraldo (Ed.), Las plagas de langostas en
América Latina: una visión interdisciplinaria. San José, Costa Rica: Editorial Nuevas Generaciones.

Blanco, R. (1984). Obispos, Arzobispos y representantes de la Santa Sede en Costa Rica. San José, Costa Rica: EUNED.

Borel, C. (1934). Datos meteorológicos del país. En L. Bergna y A. Zen (Eds.), Anuario General de Costa Rica. 1934 (p. 234). San José, Costa Rica: Imprenta Borrasé Hnos.

Borel, C. E. y Merino, J. (1934). La Predicción del Tiempo mediante el Radio. En L. Bergna y A. Zen (Eds.), Anuario General de Costa Rica. 1934 (pp. 235-241). San José, Costa Rica. Imprenta Borrasé Hnos.

Botey, A. M. (2005). Costa Rica entre guerras: 1914-1940. San José, Costa Rica: EUCR.

Budowski, G. y Schreuder, G. F. (s.f.). The Climate at Turrialba. Turrialba, Costa Rica: IICA.

Carvajal, G. y Botey, A. M. (1991). Historia del Ferrocarril al Atlántico: Cien años del primer recorrido de una 
locomotora entre San José y Limón. 1890-1990. Herencia, 3 (1-2), 135143.

Conejo, A. (1972). Materiales para una biobibliografía costarricense del Dr. Henri Pittier Dormond. Tesis para optar por el título de Licenciatura en Ciencias y Letras con especialización en Geografía e Historia, Facultad de Ciencias y Letras, Universidad de Costa Rica.

De La Cruz, V. (1984). Las luchas sociales en Costa Rica. 1870-1930. San José, Costa Rica: ECR y EUCR.

Díaz, R. (2003). El proceso de institucionalización de la meteorología en Costa Rica (18871949). Tesis para optar por el título de Licenciatura en Historia, Escuela de Historia, Facultad de Ciencias Sociales, Universidad de Costa Rica.

Díaz, R. (2004/05). La tormenta tropical de 1887 y su paso por las fuentes históricas costarricenses. Revista Estudios (18/19), 39-56.

Eakin, M. C. (1999). The origins of modern science in Costa Rica: The Instituto Físico-Geográfico Nacional, 1887-
1904. Latin American Research Review, 34 (1), 123-150.

Fernández, W. (1997). Elliott Coen París: 1921-1997. Tópicos Meteorológicos y Oceanográficos, 4 (1), 3-4.

García, M. E. (1992). Sociedad, política y enclave bananero. Un estudio comparativo: Costa Rica (18841938) y Honduras (1902-1938). Tesis para optar por la Maestría en Historia, Sistema de Estudios de Posgrado, Universidad de Costa Rica.

Gutiérrez, P. N. (1906 junio 10). Resumen de observaciones en el mes de enero de 1906. Boletín de la Sociedad Nacional de Agricultura, I (1), 1521.

Gutiérrez, P. N. (1906 agosto 10). Resumen de observaciones en el mes de abril de 1906. Boletín de la Sociedad Nacional de Agricultura, I (6), 9496.

Gutiérrez, H. (1981). La ingeniería en Costa Rica: 1502-1903 ensayo histórico. Cartago, Costa Rica: Editorial Tecnológica de Costa Rica.

Hartman, C. (1991). Arqueología costarricense (textos publicados y diarios 
inéditos). San José, Costa Rica:

EUCR.

Hernández V., Alfredo E. y Jiménez, W.

(1951). La Dirección General de

Estadística y Censos investiga para

servir a la Nación. San José, Costa

Rica: DGEC, Sección de

Publicaciones.

Holmes, D. C. (1966). La atmósfera, mar sin playas. Ciudad de México, México: La Prensa.

Instituto Geográfico Nacional (IGN).

Comisión Organizadora del

Centenario (1989). Edición

conmemorativa. Cien años. Instituto

Geográfico Nacional. San José,

Costa Rica: IGN.

Jiménez, C. M. (1962). Historia de la aviación en Costa Rica. San José, Costa Rica: Imprenta Elena.

Kepner, C. D. y Soothill, J. H. (1949). El imperio del banano. Ciudad de México, México: Ediciones del Caribe.

Lizano, O. G. y Fernández, W. (1996 julio). Algunas características de las tormentas tropicales y de los huracanes que atravesaron o se formaron en el Caribe adyacente a
Costa Rica durante el período 1886-

1988. Tópicos Meteorológicos y

Oceanográficos, 3 (1), 3-10.

Meléndez, S. (1996). Diagnóstico de amenazas naturales y vulnerabilidad física de la población en el Área Metropolitana. San José, Costa Rica. Tesis para optar por la Maestría en Geografía, Sistema de Estudios de Posgrado, Universidad de Costa Rica.

Merino, J. (1943 junio). Precipitación pluvial durante el mes de mayo de 1943. Revista del Instituto de Defensa del Café, XIII (104), 415.

Ministerio de Recursos Naturales, Energía y Minas (MIRENEM), Instituto Meteorológico Nacional (IMN) (1988). Catastro de las series de precipitaciones medidas en Costa Rica. San José, Costa Rica: IMN.

Molina, F. (1851). Bosquejo de la República de Costa Rica. Nueva York, Estados Unidos: Imprenta de S. W. Benedict.

Molina, I. (2005). Del legado colonial al modelo agroexportador. Costa Rica 1821-1914. San José, Costa Rica: EUCR. 
Murchie, A. G. (1981). Imported spices: A Study of Anglo-American Settlers in Costa Rica. 1821-1900. San José, Costa Rica: Ministry of Culture, Youth and Sports.

Murillo, C. (1995). Identidades de hierro y humo. La construcción del Ferrocarril al Atlántico 1870-1890. San José, Costa Rica: Porvenir.

Ortiz, L. E. (2002). Historia de la aviación en Costa Rica. San José, Costa Rica: MARS Editores.

Osejo, R. F. (1948). Exposición al C. Ministro General sobre el Valle de Matina 1833. Revista de los Archivos Nacionales, XII (3-4). San José, Costa Rica: Imprenta Nacional.

Peraldo, G. y Rojas, E. (1998). La deslizable historia del Ferrocarril al Caribe de Costa Rica. Anuario de Estudios Centroamericanos, 24 (1-2), 97128.

Pérez, H. (1997). Breve historia contemporánea de Costa Rica. Ciudad de México, México: FCE.

Román, C. (1987). Almanaque mundial 1988. Ciudad de Panamá, Panamá: Editorial América.
Sáenz, F., 2014: El ciclo diurno de la precipitación en el Caribe de Costa Rica: observaciones y simulaciones con un modelo dinámico regional. Tesis para optar por el grado de Licenciatura en Meteorología, Escuela de Física, Facultad de Ciencias, Universidad de Costa Rica.

Sáenz, J. F.; Fernández, J. A. y Muñoz, M. G. (2001). Las Primeras Damas de Costa Rica. San José, Costa Rica: ICE.

Salguero, M. (1981). La Costa Rica que no todos conocemos. San José, Costa Rica: Editorial Stvdivm.

Schaufelberger, P. (1935 setiembre). Algunos datos meteorológicos de Costa Rica. Revista del Instituto de Defensa del Café, II (12), 283-294.

Scherzer, K. von y Wagner, M. (1944). La República de Costa Rica en CentroAmérica. San José, Costa Rica: Lehmann.

Secretaría de Instrucción Pública de la República de Costa Rica (SIPRCR) (1889). Anales del Instituto FísicoGeográfico Nacional, II (I). San José, Costa Rica: Tipografía Nacional. 
Solano, F. y Páez, J. (1991). Semblanza de un Profesor de Ciencias: Don Elliott Coen París. En: Á. Ruiz (Ed.). Ciencia y tecnología en la construcción del futuro (pp. 247 262). San José, Costa Rica: Guayacán.

Solano, F. J. (1999). El proceso de institucionalización de la meteorología en Costa Rica en el siglo XIX. Tesis para optar por el grado de Licenciatura en Historia, Escuela de Historia, Facultad de Ciencias Sociales, Universidad de Costa Rica.

Stewart, W. (1976). Keith y Costa Rica. San José, Costa Rica: ECR.

U.S. Department of Comerce. National Oceanic and Athmospherics Administration (NOAA) (1981). Tropical Cyclones of the North Atlantic Ocean, 1871-1980. Ashville, North Carolina, USA: NOAA.

Velásquez, R. Á. (2000). Turrialba. Un vistazo al pasado. Turrialba, Costa Rica: s.e.

Velásquez, R. Á. (2002). Anécdotas y remembranzas de Turrialba.
Turrialba, Costa Rica: Imprenta CATIE.

Viales, R. (1993). Región Atlántica costarricense y el enclave bananero: del esplendor a la crisis, 1927-1950. Tesis para optar por la Maestría en Historia, Sistema de Estudios de Posgrado, Universidad de Costa Rica.

Viales, R. (1998). Después del enclave. 1927-1950: un estudio de la región atlántica costarricense. San José, Costa Rica: EUCR y Museo Nacional de Costa Rica.

Viales, R. y Clare, P. (2009). El Estado, lo transnacional y la construcción de comunidades científicas en la Costa Rica liberal (1870-1930). La construcción de un "régimen de cientificidad". En: R. Viales, J. A. Amador y F. J. Solano (Eds.). Concepciones y Representaciones de la Naturaleza y la Ciencia en América Latina (pp. 97-109). San José, Costa Rica: Universidad de Costa Rica, Vicerrectoría de Investigación.

Zelaya, C. (1971). El Bachiller Osejo, II. San José, Costa Rica: ECR. 